\title{
LOS ARCOS DE TRIUNFO Y LAS PORTADAS RELIGIOSAS EN LA NUEVA ESPAÑA
}

\section{Por Pedro Rojas}

Quiza ninguna forma de conocimiento sea tan rica, reveladora y veraz como la que proviene del trato con los objetos, es decir, la que resulta de enlazar las ideas con la experiencia directa de las cosas.

Esta reflexión me la he hecho muchas veces y estoy convencido de que es válida y productiva. En los últimos tiempos, con motivo del estudio que emprendi sobre la arquitectura de la ciudad de México en el siglo xvirr, al ir $y$ venir, reiteradamente, por nuestras calles, me sentí nuevamente atraiclo por el aspecto de las portadas de los templos. Todas ellas nos son conocidas, familiares, y se sabe mucho de sus estilos, épocas y autores, no obstante lo que me detuve ante algunas para admirarlas una vez más y recibir las impresiones de conjunto; otras veces las vi de cerca, en detalle, y descubri pormenores hasta entonces inadvertidos.

Así, en un momento dado, me hallé ante el templo de San Fernando y tuve la impresión de que la parte inferior de su portada era como un solemne arco de triunfo romano. Inmediatamente, sin proponérmelo, asocié la idea del arco de triunfo a las portadas frontales y laterales de la catedral de México y repetí la experiencia de contemplarlas, obteniendo análogo resultado. La representación del arco de triunfo se me manifestó muy clara con sólo hacer abstracción del segundo cuerpo de cada portada. Pero hubo algo más: me impresionó la armonfa que emanan por la justeza de sus proporciones, armonía que se ve contrariada en San Fernando a causa de tener hundida una buena parte de su fachada.

Con esos antecedentes me propuse hacer una investigación que me llevara a establecer la posible relación formal de esas portadas entre sí y con los arcos de triunfo romano, e intentar al mismo tiempo hallar la explicación de su belleza. El presente trabajo reúne el fruto de ese propósito y marca un camino tentativo para realizar un estudio más a fondo de la estética de nuestra arquitectura colonial.

El punto de partida del presente trabajo estriba en considerar que las portadas frontales y laterales de la catedral de México obedecen a la concepción clásica del arco cle triunfo que se manifiesta también en la del templo de San Fernando. Que los arquitectos de ambos tem- 
plos, separaclos por las fechas de diseño y obra que van de mediados del siglo xv'I a la mitad del xvin, persisten en la observancia de análoga idea. $Y$, al mencionar esas portadas, es muy probable que se pueda decir lo mismo de toda la familia estilistica a la que ellas pertenecen.

Las vivencias que concurren en dicho punto de partida son las de observación de las portadas poniendo en juego la imaginación para abstraer los segundos cuerpos y dejar clara y distinta la forma de los primeros. (Figuras 4 y 5.) En el caso de la portada de San Fernando la observación en este sentido es más fácil por la circunstancia de que el diseñador destacó mediante un resalto, en forma de biombo, todo el primer cuerpo y dejó en un plano rezagado el segundo y el remate, lo que constituye un indicio muy importante para la hipótesis planteada en este trabajo acerca del posible origen estilístico de tales portadas. Por otra parte, y para facilitar las cosas, se ha considerado innecesario el examen de las portadas secundarias de la catedral, concentrando la atención en la principal.

El planteamiento de esas portadas ejemplares es el de composiciones de dos cuerpos, más el área de remates. La estructura de las mismas aparece formada por un reticulado clásico de elementos verticales (columnas o pilares) y horizontales (entablamentos). En ambas, la calle central comprende la puerta y el muy novohispánico relieve historiado en lo alto, en el segundo cuerpo. Los intercolumnios, a su vez, incluyen hornacinas para alojar estatuas. Y hay un elemento más, de particular importancia, que es el ático del primer cuerpo, mismo que juega un doble papel, originando que se le tenga por pedestal del segundo cuerpo y no como ático integrado al primero. En efecto, esa gran faja o cuerpo de arquitectura que corre sobre la cornisa, funciona de los dos modos y al tomársele por pedestal, de éste se hace arrancar el segundo cuerpo, es decir, a partir de la cornisa del primero. Sin embargo, no es exactamente asi, pues ese cuerpo horicontal es, ante todo, el ático correspondiente al diseño del arco de triunto en que está basada la portada. También debe hacerse la observación de que la ambigüedad que presentan estas portadas no se limita al doble papel del ático, sino al juego que hacen los órdenes, pues en el arco de triunfo clásico va el orden compuesto y en los ejemplos aludidos, es el toscano en la catedral y en San Fernando el capitel toscano con un friso barroco.

Ahora bien, desligando como y se ha dicho, intencional y visualmente el primer cuerpo de sus agregados superiores, la visión del arco de triunfo se vuelve clarísima y hace posible que produzca el goce 
DOI: http://dx.doi.org/10.22201/iie.18703062e.1971.40.934

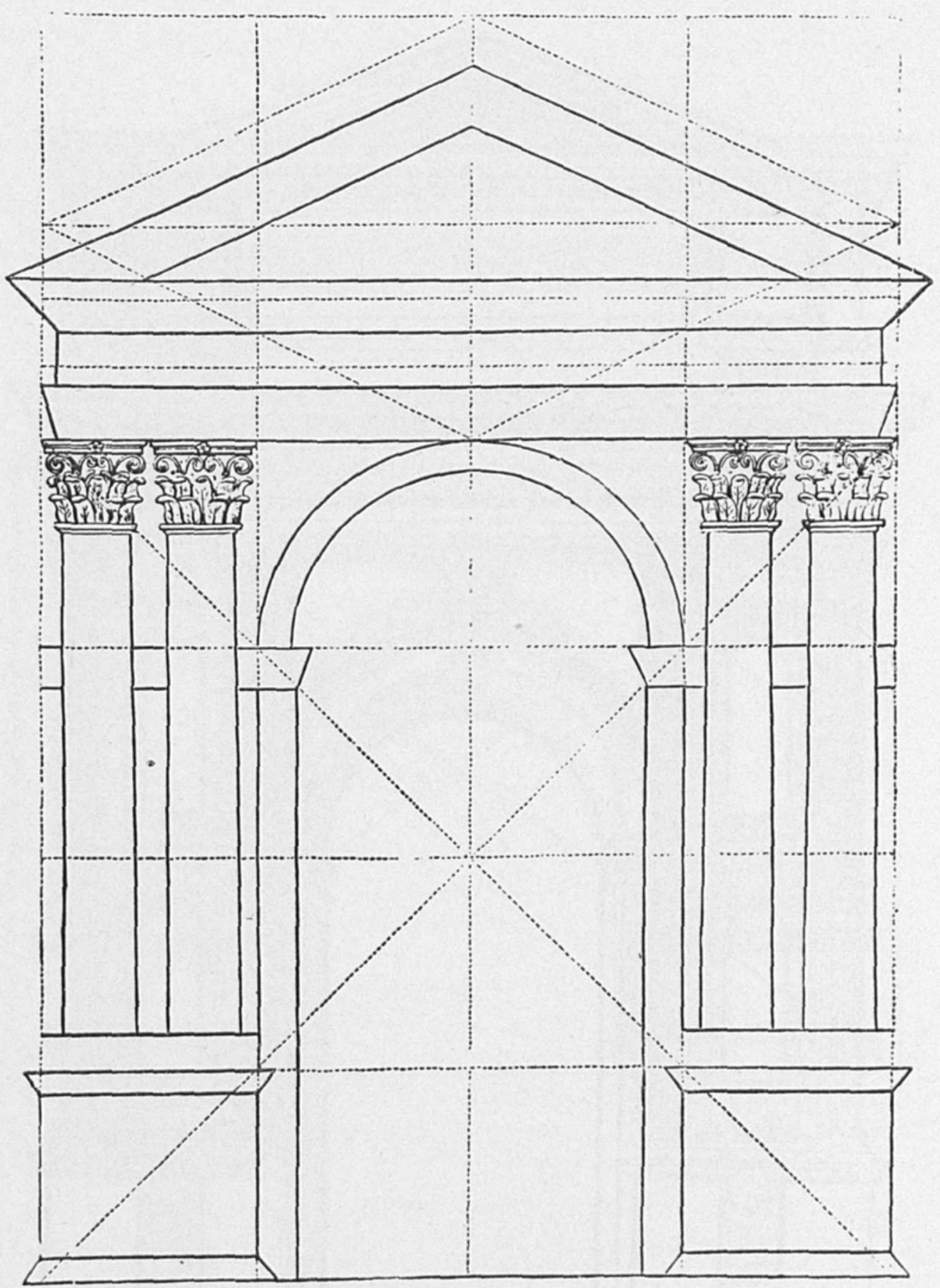

1. Hypnerotomachia Poliphili. Arco de paso. 
DOI: http://dx.doi.org/10.22201/iie.18703062e.1971.40.934

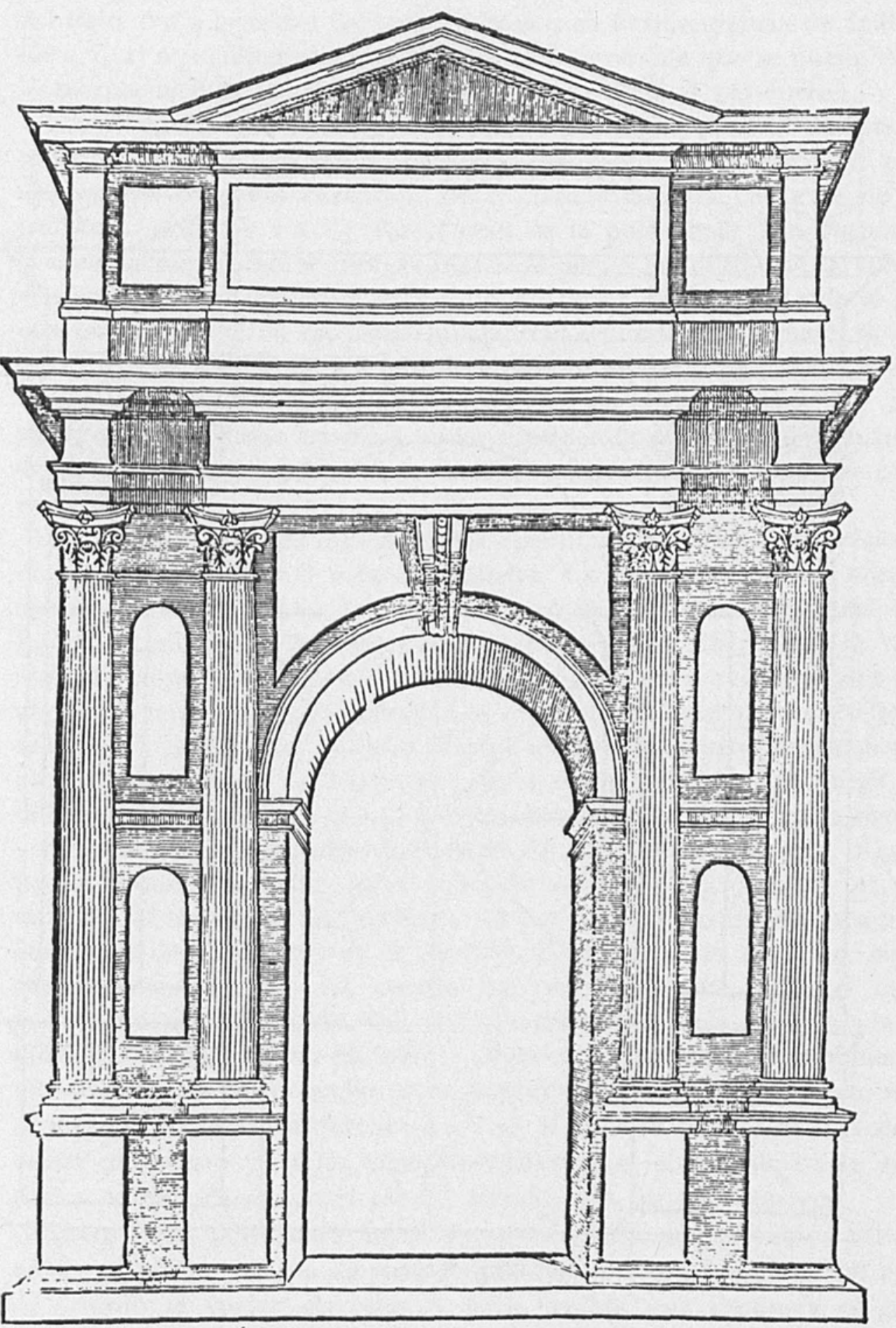

2. Sebastián Serlio. Arco de triunfo. 
DOI: http://dx.doi.org/10.22201/iie.18703062e.1971.40.934

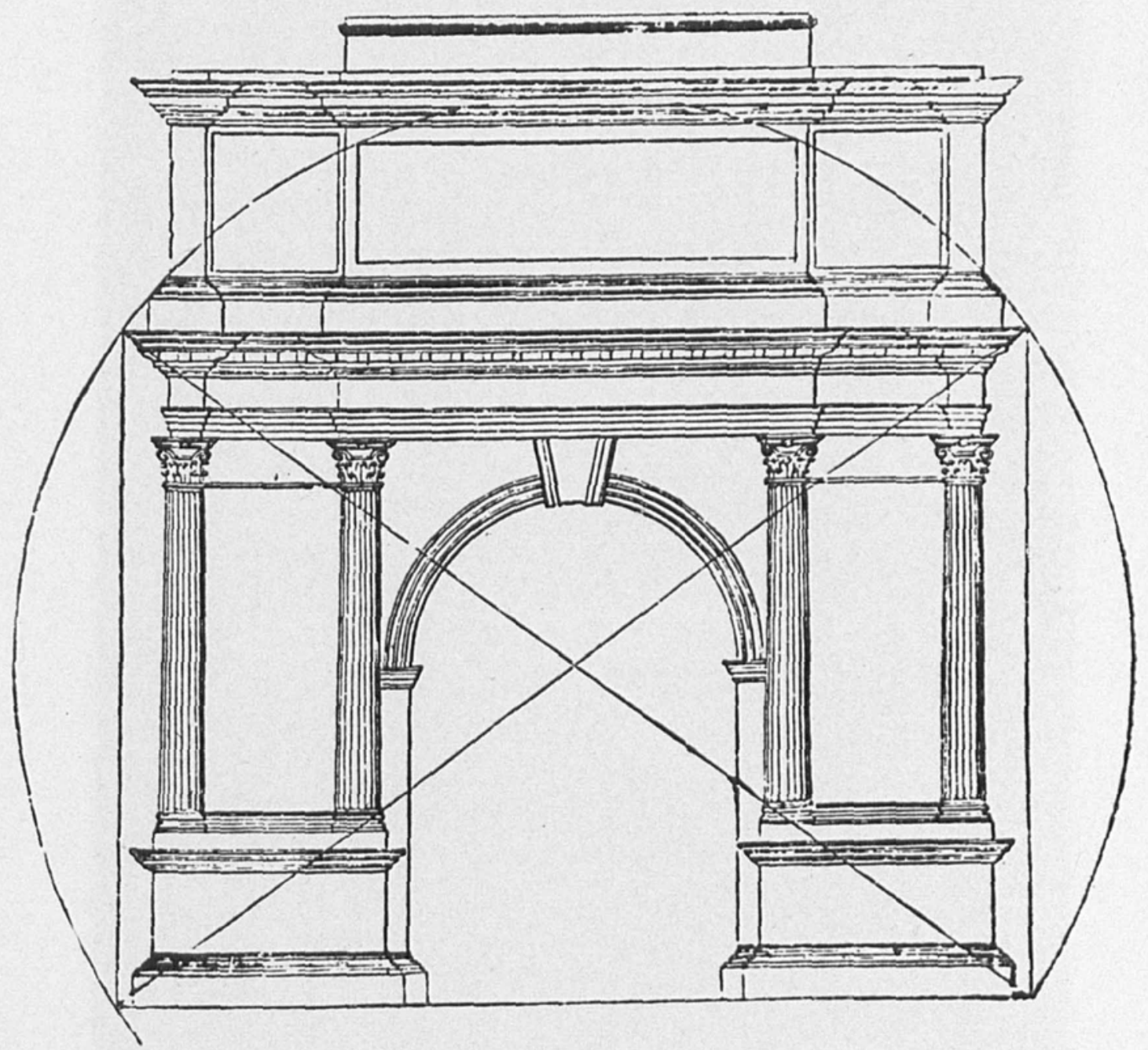

3. Arco de Sergio, en Pola. 
DOI: http://dx.doi.org/10.22201/iie.18703062e.1971.40.934

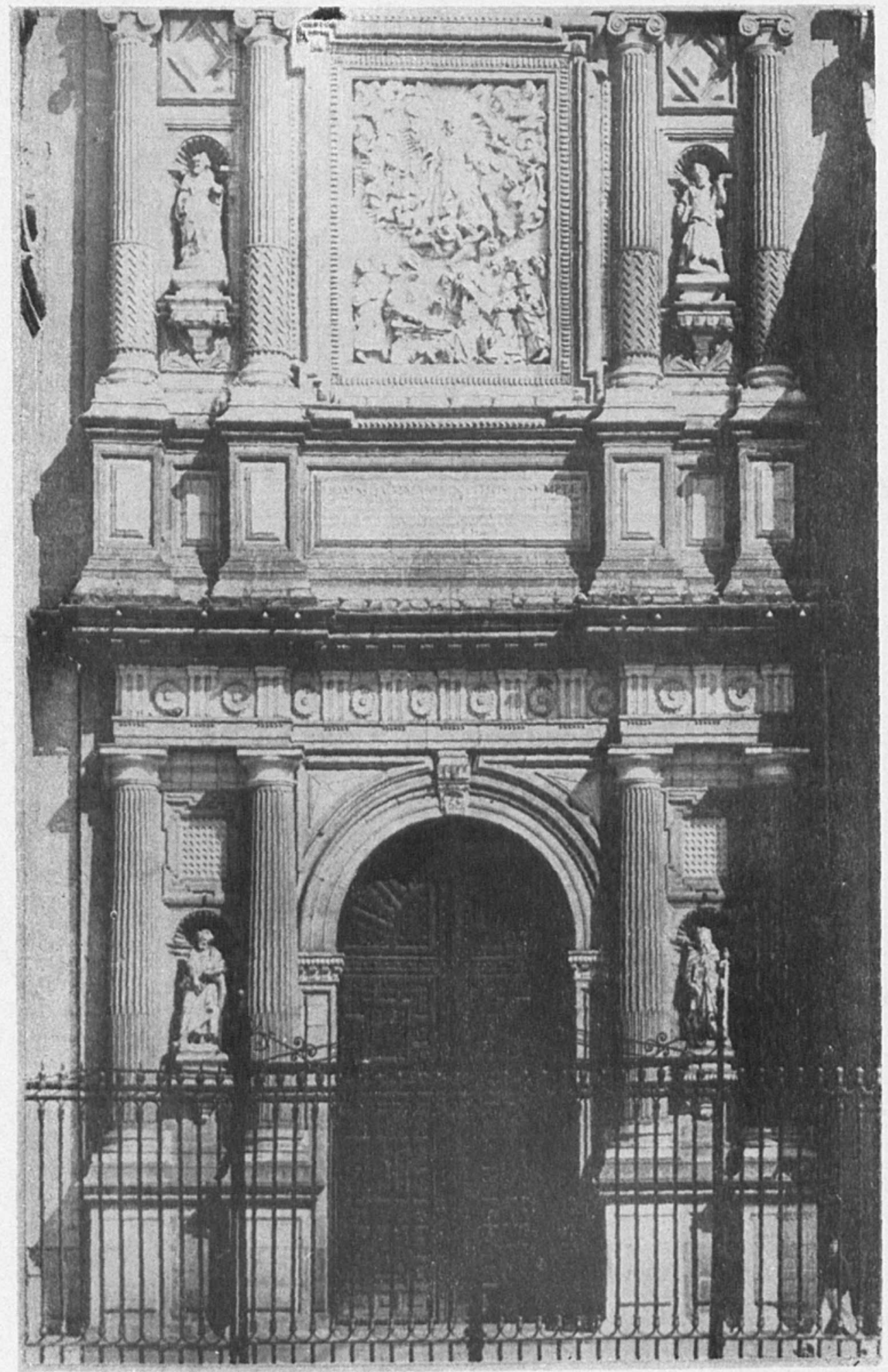

4. Catedral de México. Portada Principal. Foto Pedro Rojas. 
DOI: http://dx.doi.org/10.22201/iie.18703062e.1971.40.934

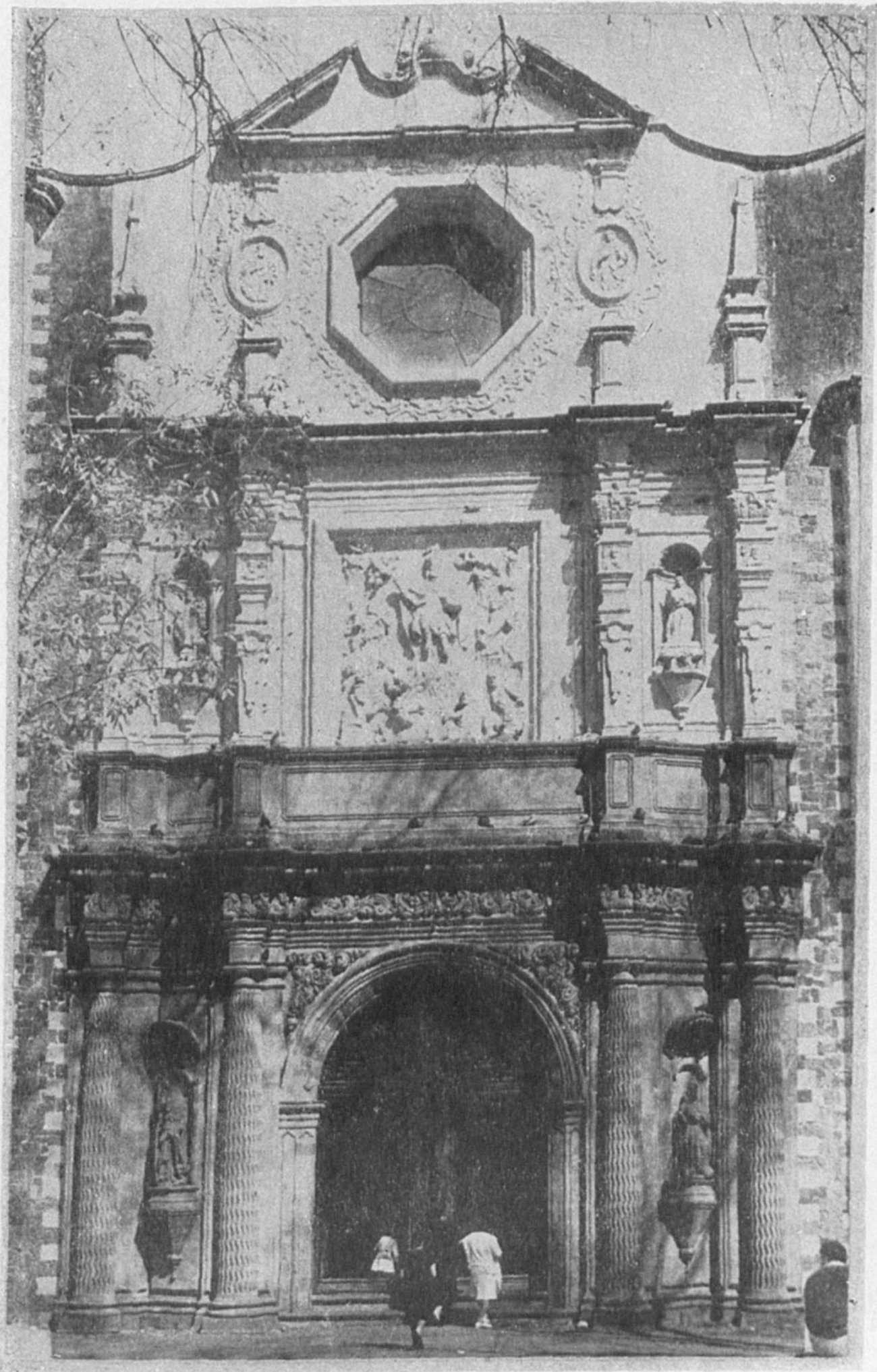

5. Portada del templo de San Fernando. Foto Pedro Rojas. 


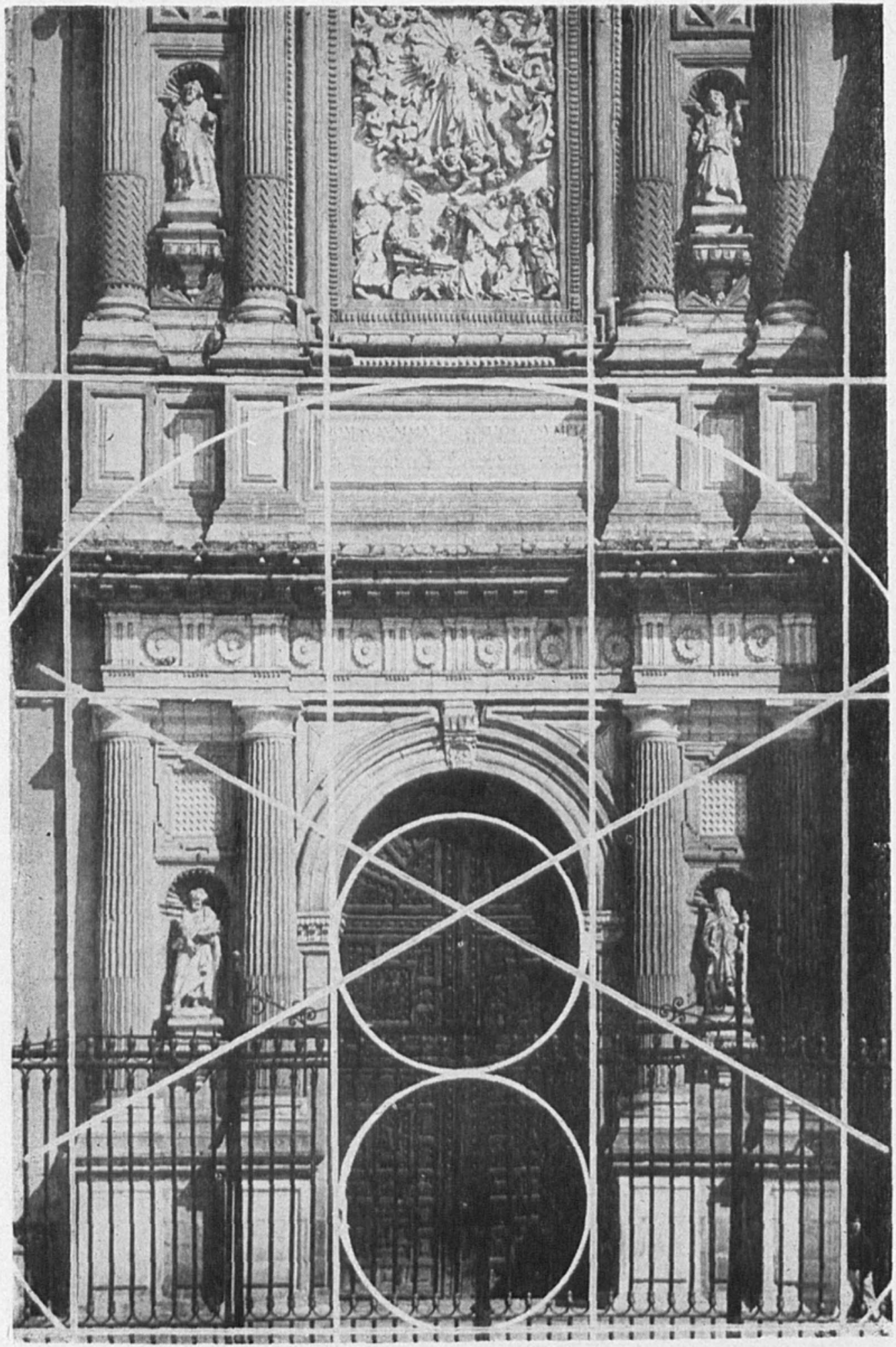

6. Portada principal de la catedral de México. Hipótesis de los trazos más importantes. Foto Pedro Rojas. 


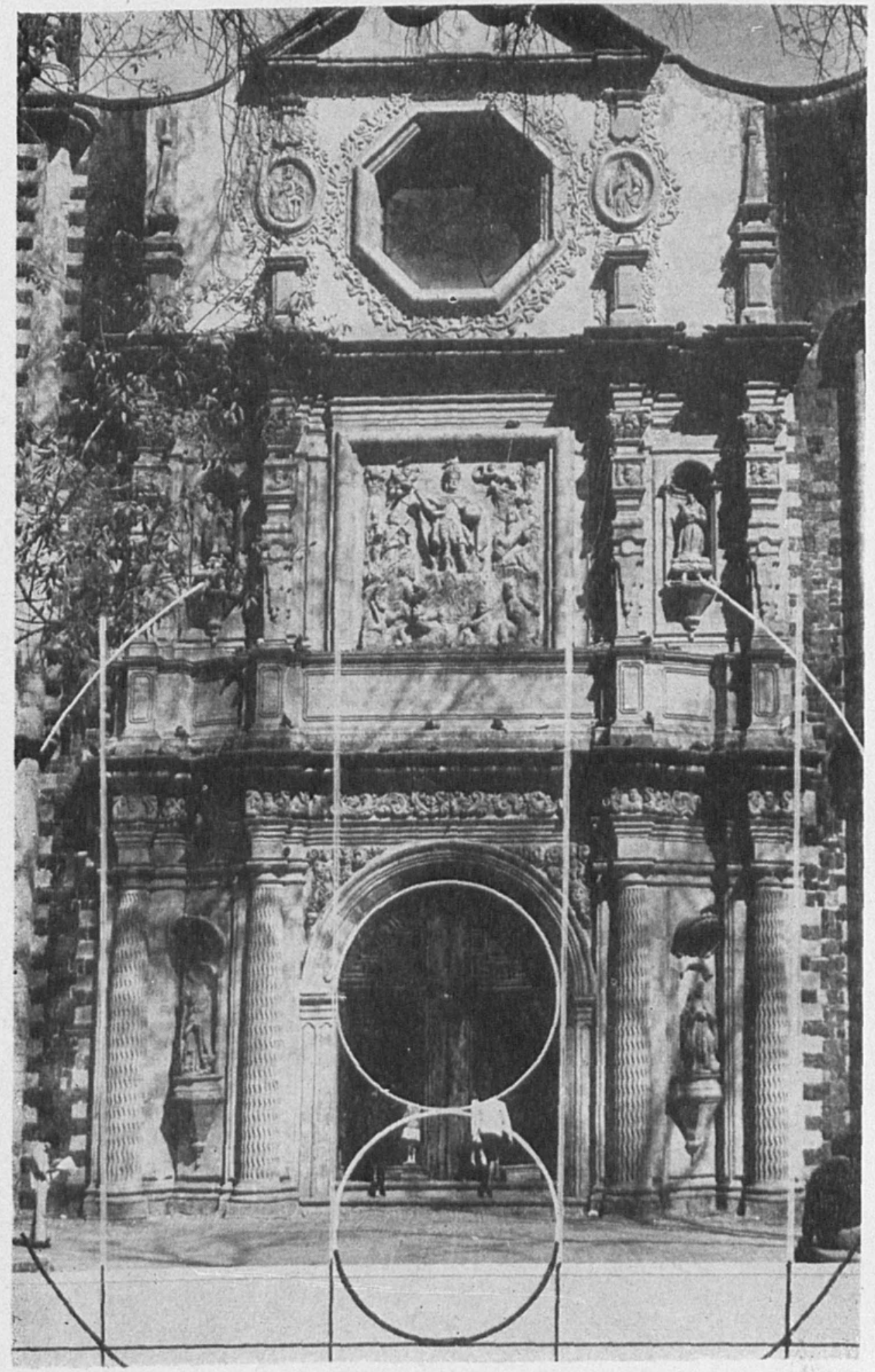

7. Portada del templo de San Fernando. Hipótesis de Ios trazos más importantes. Foto Pedro Rojas. 


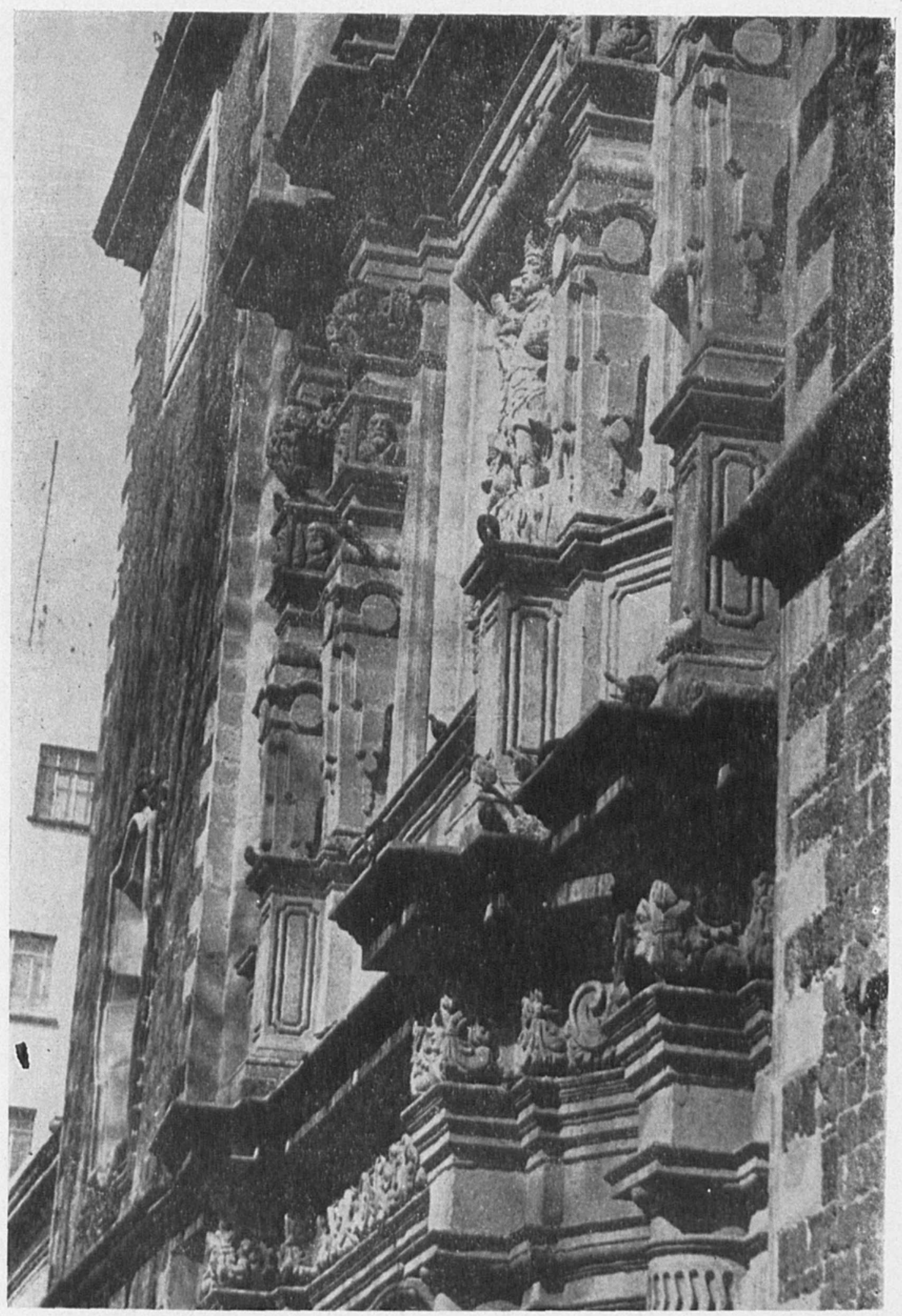

8. Portada del templo de San Fernando. Detalle del resa!to del primer cuerpo. Foto Pedro Rojas. 
estético que provocan obras como estas que reactualizaron aquel tipo de monumento tan lógico, armónico y representativo de la arquitectura romana antigua.

Pero hay más, en los áticos novohispánicos de referencia, aparecen sendas inscripciones, las que por sí solas llevarian a identificarlos como tales áticos y no como simples basamentos.

Todas estas observaciones se ven corroboradas por el revelador détalle de diseño que contiene la portada de San Fernando: el arquitecto, en plena época de nuestro barroco, se dio el lujo de trazar la portada marcando el primer cuerpo (incluyendo el ático) haciéndolo adelantarse unos cincuenta centímetros en su parte central, con movimientos de planos de biombo, como ya se ha dicho, lo que no hizo con los elementos del segundo cuerpo (cuatro estipites, relieve historiado, nichos), los que dejó dispuestos en el mismo plano que el resto de la fachada (Figura 8). Con el resalto del primer cuerpo hasta el ático, y nada más que ése, la imagen de un arco de triunfo resplandece nitida y tangible. Sería difícil negar que esta forma de presentar las cosas sea la manifestación de una conciencia operante, sobre la importancia y significación que tenía el primer cuerpo, dando al arco de ingreso al templo la categoria y dignidad monumental del más honroso edificio romano.

A todo esto, que sirve para la identificación de lo aparente, hay que agregar la experiencia de las proporciones $y$, por consiguiente, de la armonía de las composiciones. Es un poco difícil percatarse por la mera contemplación de las portadas, de las normas que rigen sus trazos. Se requiere acudir a la prueba de los esquemas, prueba que, por lo demás, evita el posible error de la mera vista, dado que muy aparte de que se tenga o no entrenado el ojo para visualizar las proporciones, se tropieza con la dificultad del hundimiento de los edificios. Mediante esquemas que toman en cuenta las genuinas dimensiones, salta a la vista la solución geométrica que se dio a las composiciones.

Para lograr, entonces, la certeza de que los primeros cuerpos de las portadas son como se ha indicado y están inspiradas en la concepción del arco de triunfo romano, procede, finalmente, revisar en forma sumaria los antecedentes y bases teóricas de este tipo de monumento. De alcanzar esa certeza, será posible disponer de una idea rectora para juzgar en mejores condiciones la estética esencial de buen número de portadas coloniales y no solamente de las dos abordadas en este trabajo.

Conocemos numerosos ejemplos de arcos de triunfo romanos y sabe- 
mos cómo se les supo valorar durante el Renacimiento. Vitrubio no los menciona, por lo que es de suponer que en su forma permanente no se remontan más allá de la época de Augusto. Se dice que el arco de triunfo "pertenece al tipo general de la arcada: es una arcada ricamente ornamentada, que lleva encima un ático donde se desarrolla la inscripción". 1 Pero eso no es todo. La composición del arco de triunfo se hacia en torno a uno o tres arcos de paso, buscando dar proporciones lógicas a la masa de construcción, y, por complemento, a las partes ornamentales. Estas últimas eran, básicamente, columnas pareadas asentadas en pedestales $y$, además, el entablamento. El ático servía para mostrar la inscripción dedicatoria y sustentar los grupos escultóricos superiores. En ciertos casos excepcionales, el arco remataba en un frontón o llevaba un segundo cuerpo. Serlio, fuente de modelos para los arquitectos de habla hispana, reprodujo el de Gavii, Verona, que mostraba un frontón antepuesto al ático, y diseñó uno con ese elemento griego sobre el ático. De ordinario no había tal frontón y sí algunos resaltos como para dar apoyo a las figuras superiores.

La idea orientadora acerca de las proporciones surgió en el Renacimiento muy probablemente a partir de la solución que se encuentra en el libro Hypnerotomachia Poliphili. Siguiendo a Vitrubio, en quien las proporciones debian basarse en el cuadrado -que es la figura geométrica que da las proporciones humanas, pues un hombre tiene la misma estatura que la longitud de sus brazos abiertos- el Sueño de Polifilio mostró en un esquema la posibilidad del trazo de los arcos de triunfo con fundamento también en un cuadrado para la composición de la cornisa al suelo, y de medio cuadrado más para el entablamento y el remate. En el esquema incluyó un reticulado que formarían simétricamente 16 cuadrados iguales en la parte inferior y ocho en la superior, suficientes para situar los diversos elementos de composición (Figura 1). ${ }^{2}$

[El Hypnerotomachia Poliphili atribuido a Fra Francesco Colonna $(\dagger$ 1527), publicado por primera vez en lengua italiana por Aldus Manutius, en Venecia, el año de 1499, ha sido considerado "el más bello libro editado en el siglo $\mathrm{xv}^{\prime \prime}{ }^{3}$ Se piensa que el presunto autor

1 Auguste Choisy, Histoire de L'Architecture, Editions Vincent, Fréal \& Cie., Paris, 1954, vol. 1, p. 463.

2 Joseph Gwilt, F.S.A. y F.R.S.A., An Encyclopaedia of Architecture, Longmans, Green, and Co., London, New York and Bombay, 1899, Fig. 1048.

8 Encyclopedia of World Art, McGraw-Hill, New York, 1959-1968, vol, vi, p. 688. 
fue un sabio anticuario, amigo de Craso, en Verona (Leonardus Crassus, vecino de los estados del duque de Urbino). ${ }^{5}$ El libro, cuyo tema es el amor de Polifilio por Polia, ${ }^{6}$ aparte de valioso por el texto $y$. por la bella presentación tipográfica, se piensa fue ilustrado con los grabados hechos por Durero para la edición de la obra de Horapollon de Andros, descubierta en el siglo xv, ${ }^{7}$ lo que contribuyó a darle mayor interés. Empero, el texto, redactado para exaltar, "más emocional e imaginativamente, que en forma racional" el sentimiento por la antigüedad considerándola "sancta e veneranda", 8 contiene un conjunto de exposiciones sobre diversos tópicos de arquitectura, simbología y otros temas humanísticos, tratados en forma poética y destinados a introducir en el gusto por la antigüedad clásica: para Fra Colonna "el retorno a la antigüedad es concebido como una transformación y renovación del interior del hombre, acompañada por todos los ritos de una real iniciación".. ${ }^{9}$

Sebastián Serlio, años después de publicado dicho Sucño, desarrolló el estudio de varios arcos de triunfo con un carácter más formal pero dentro del mismo espiritu humanista que exaltó los valores de la antigüedad clásica. Vino a ser importante establecer sus elementos, simetria y proporciones. Así, hizo observaciones acerca de las diversas soluciones armónicas dadas a los trazos de los arcos que estudió y con ello abrió el camino que seguirian otros tratadistas y los diseñadores en general. ${ }^{10}$ En su obra se halla, incluso, el dibujo de un arco de triunfo que comprende hornacinas en los intercolumnios, a la manera como serían las difundidas en México y que están representadas, en forma muy aproximada en la iglesia de Tecali, del siglo xvi y, en forma más sencilla, en las ulteriores portadas de la catedral y San Fernando (Figura 2).

Con estos indicios acerca de modelos y proporciones, es posible hallar las soluciones logicas que rigieron las composiciones mexicanas de referencia. La forma de arco de triunfo aparece en la portada de la catedral distribuida en tres secciones verticales de un mismo valor espacial (la

- Arthur M. Hind, An Introduction to a History of Woodcut, Dover Publications, Inc. New York, 1963, vol. II, p. 493.

Encyclopedia of World Art, op. cit., vol. viI, p. 731.

6 An Introduction to a History of Woodcut, op. cit., vol. Ir, pp. 491 y 492.

7 Encyclopedia of World Art, op. cit., vol. Lx, p. 387.

8 Idem., vol. Iv, p. 131 .

9 Idem., vol. I, p. 489.

10 Sebastián Serlio Boloñés, Tercero y Quarto Libro de Architectura, Casa de Iván de Ayala, Toledo, 1557. 
sección central está ocupada por el vano de acceso y las laterales por las columnas pareadas y sus intercolumnios); el vano mencionado está determinado por dos circunferencias iguales más un ligero peraltamiento del arco; el peralte de las columnas lo dan las intersecciones de dos ejes diagonales trazados desde el centro del diámetro del arco de la puerta tal cual se ve; a su vez los límites de la composición, de la base del ático hasta el suelo, los dan las intersecciones de otras diagonales tiradas desde el punto central de una línea trazada de la parte inferior de las impostas y que sería la del diámetro del arco de no haberse peraltado. La relación general de proporciones es de tercios: tres secciones verticales equivalentes para las áreas de las columnas y del vano de ingreso; dos secciones horizontales para abarcar los basamentos y las columnas y una sección más para el entablamento y el ático (Figura 6). Como se puede notar cumple con la distribución del esquema del Sueño. Esta portada aparece inscrita dentro de una circunferencia y tiene semejanza con la del arco de Tito, en Roma, y con la del de Sergio, en Pola (Figura 3).

La portada de San Fernando difiere de la catedralicia no sólo por sus detalles barrocos sino por las proporciones: ésta es menos esbelta que la otra. Por lo demás, comprende esencialmente los mismos elementos (columnas pareadas, entablamento, ático y hornacinas). Sus partes también están regidas por tres secciones verticales con un ligero predominio de las laterales sobre la central (la del vano); la arcada obedece a dos circunferencias, como la de la catedral; toda la composición, hasta la altura del ático, está englobada por una circunferencia que toca las esquinas de aquél y las de los pedestales; en cambio, es difícil cstablecer otras relaciones entre las partes debido al acomodo que se les dio dentro de un rectángulo en vez del cuadrado más el rectángulo, que señalaba el esquema del Sueño de Polifilio (Figura 7).

Las consideraciones anteriores forman parte de un ensayo para explicar la impresión de armonía y belleza que produce la contemplación de esta clase de formas monumentales. Intentan traspasar la experiencia inmediata, que cautiva la atención, y también rebasar los límites de la pura descripción de los elementos que integran las composiciones. Llevan, en resumen, el deseo de conocer mejor la morfología estética abordando cada objeto arquitectónico en su propia complejidad. 